\title{
FORMACIÓN, PERSISTENCIA Y DESTRUCCIÓN DE \\ UN REPERTORIO TRADICIONAL DE MÚSICA
}

\author{
C. Rodriguez Suso, "Kalam»
}

Non nova sed nove

\section{SIC INCIPITUR}

Entre los libros copiados en Occidente durante los siglos IX y $\mathrm{X}$ se encuentran algunos que poseen características peculiares. Se trata de ciertos libros litúrgicos. Libros concebidos, por tanto, para ser utilizados en actos rituales. En estos actos se realiza la operación de transformar el tiempo ordinario en un tiempo-otro 1 . Por tanto, tales libros son instrumentos que operan sobre el tiempo, tal y como el templo, edificio sagrado, opera sobre el espacio. Tiempo y espacio, los dos parámetros fundamentales de la experiencia humana ${ }^{2}$, se entrecruzan asi en esa particular circunstancia que llamamos «rito». En su origen, ambas palabras tuvieron una etimologia vecina: Templum-Tempus. Las dos designan el movimiento; la una en su aspecto espacial; la otra en su aspecto temporal ${ }^{3}$. Lo que permiten al hombre es sacramentalizar el movimiento; es decir, desplazarse, cambiar la ubicación temporal y espacial, abandonar el espacio y tiempo ordinarios y trasladarse sin peligro al espacio y tiempo sagrados: Ex-stare ${ }^{4}$. La antigüedad de

1J. Hant, Le Symbolisme du Temple Chrétien, Eds. de la Maisnie, Paris 1962, p. 147 .

${ }_{2}^{\text {A }}$. Gourevitch, Les Catégories de la Culture Médiévale, Gallimard, Paris $1983(1972)$, p. 33.

${ }^{3}$ M. Ellade, Lo Sagrado y lo Profano, Guadarrama, Madrid 1967 (1957), p. 68.

4 A. GoUREVITCH, op. cit., p. 37. 
esta asociación es insondable porque responde a una experiencia primordial 5 .

Los libros litúrgicos son, pues, objetos que permiten a quien los puede y sabe usar en la manera debida, realizar una operación mística: reintegrar la dispersión del ser, remediando la tragedia del tiempo. Obedecen a la indicación del Salmista:

\section{Dinumerare nos doce dies nostros, ut perveniamus ad sapientiam cordis 6 .}

Por ello, deben ser utilizados adecuadamente, con precisión, sin errores. Las palabras sagradas que contienen requieren una adecuada manera de ser dichas: algunos de esos libros copiados entre los siglos IX y X llevan, junto a los textos sagrados, preciosas indicaciones sobre el modo en que deben promunciarse, es decir, música.

Una melodía gregoriana, por tanto, sólo puede ser enfocada al ser examinada en aquel lugar que la liturgia le asigna? ${ }^{7}$ No puede exagerarse nunca el interés de la liturgiología para el musicólogo; antes al contrario, su importancia no se puede valorar suficientemente hasta que se experimenta ${ }^{8}$. Pues éste es el lugar en que debe situarse el estudio de esta música medieval: dentro del acto litúrgico, como ornamentación y exaltación de la palabra sagrada. Es parole-chantée 9 . En la mente del cantor entrenado, cada versículo, cada frase, cada palabra resuenan con su propia entonación, ligadas para siempre ${ }^{10}$ la pa-

${ }^{5}$ En su conocido Die vier Weltalter der Musik, W. Wiora cita el texto de un himno sumerio en que se equiparan ambos términos. Véase W. WIORA, Les Quatre Ages de la Musique, Payot, París, p. 45.

6 Psal. LXXXIX $(X C), 12$.

$7 \mathrm{M}$. SCHNEIDER, «Consideraciones acerca del Canto Gregoriano y la voz humana», Arbor XIV, núm. 48, 1949. No indica que es traducción de "Vom gregorianischer Choral,3, Der katolische Gedanke X, 1936.

$8 \mathrm{~F}$. LL. HARRISON, «Music and Cult: The functions of music in social and religious systems", Perspectives in Musicology, editado por B. S. Brook, E. O. D. Downes y S. van Solkema, Norton, Nueva York 1972, p. 315.

${ }^{9}$ Dom E. CARDine, Première Année de Chant Grégorien, Inst. Pont. de Musique Sacrée, Roma 1975, p. 33.

${ }^{10} \mathrm{El}$ análisis del fenómeno nos conduce así a los métodos de la Eimomusicologia, para la que texto, música, danza y rito, constituyen una unidad inseparable. Así lo aconseja también la consideración del carácter extrovertido de la práctica religiosa medieval y la concepción esencialmente dramática del rito, antes de que se llevara a cabo la casi total exclusión de los legos en su parte activa. Véase, por ejemplo, K. Young, The Drama of the Medieval 
labra y la música, que devienen asi realidades estrechamente asociadas $^{11}$; asociadas entre sí y asociadas a la percepción temporal por su escalonamiento litúrgico, pues un periodo temporal no equivale a otro aunque ambos tengan la misma duración:

Quare dies diem superat et iterum lux lucem, Et annus annum a sole?

A Domini scientia separati sunt ${ }^{12}$.

Esta asociación es lo que les otorga su carácter objetivo, ya que en todo arte sagrado la estética se liga jerárquicamente a la cosmologia, y por ella a la ontología y a la metafísica ${ }^{13}$. Así se determina su carácter esencial: ser simbólicas, o sea, traducir y ejecutar la correspondencia que liga los diversos grados de realidad ${ }^{14}$. Actúan, pues, según la ley de analogía ${ }^{15}$, por la cual la mente es llevada del mundo de las apariencias a la contemplación del orden divino ${ }^{16}$. No se trata, por tanto, de un mero juego poético con símbolos, sino, muy al contrario, de un método epistemológico que en la Edad Media era el único considerado válido ${ }^{17}$. Por eso la melodía gregoriana es, como el icono, una ventana abierta sobre la realidad divina, $y$, a la vez, la materialización de un pensamiento doctrinal. Parafraseando a san Basilio podría decirse que lo que la melodía gregoriana proclama es lo que la pintura muestra silenciosamente.

Church, Oxford 1933; E. K. Chambers, The Medieval Stage, Oxford 1963 (1903); O. HARDISON, Christian Rite and Christian Drama in the Middle Ages, Baltimore 1965.

11 M. SCHNEIDER, «Primitive Music», The New Oxford History of Music, vol. I, Oxford University Press, Londres 1957, p. 31.

12 Ecclesiasticus 33, 7-8.

$13 \mathrm{~J}$. HANI, op. cit., p. 15, La adopción de este criterio de valor es lo que nos ha permitido denominar "tradicional" al repertorio que estudiamos, siguiendo la linea de pensamiento de T. Burckhardt, A. K. Coomaraswamy, etcétera.

$14 \mathrm{~J}$. Hani, loc, cit.

15 A. GOUREVITCH. op. cit., D. 63.

$16 \mathrm{~S}$. Aurelii Augustini De Ordine L. II, c. XIV. PL XXXII, c. 1013-1014. M. SCHNEIDER, El origen Musical de los Animales-Simbolos en la Mitologia y la Escultura Antiguas, CSIC-Instituto Español de Musicologia, Barcelona 1946, pp. 3-4.

17 E. Guson, «Analogie, causalité et finalité», L'Esprit de la Philosophie Médiévale (2॰ Ed. Ren.), J. Vrin, París 1961 (1931), pp. 85-109; id., «La analogia universals, La Filosofia de San Buenaventura, Ed. Dedebec, Buenos Aires 1948 (1924), pp. 198-228. 
Este pensamiento mostrado y proclamado, si verdaderamente corresponde a una experiencia arquetípica, debe ser rememorado, repetido, imitado periódicamente ${ }^{18}$; los factores serán la memoria, la intensidad, la reiteración.

$\mathrm{La}$ memoria, porque un pensamiento doctrinal debe estar dispuesto en todo momento para ser pronunciado, es decir, debe encarnarse en el hombre. Con ello se asegura también su correcta asimilación y transmisión ${ }^{19}$.

$\mathrm{La}$ intensidad, necesaria para determinar lo cuantitativo, o sea, la exacta proporcionalidad con las dimensiones del objeto de la búsqueda y con el ansia de los que aspiran a encontrarlo. Ella estimulará a los perezosos y protegerá a los más ávidos de una experiencia demasiado cercana.

La reiteración, como medio para conseguir el éxtasis ${ }^{20}$ : el paradójico camino de la rutina, la obsesionante regularidad, marcada únicamente con los cambios que diferencian cada tiempo.

La ley de analogía actúa sobre las unidades temporales: el momento presente, la hora, el día, la época, el año, los ciclos cósmicos básicos. El día, por ejemplo, es sacralizado por la ritualización de las horas (Oficios): de Maitines a Vísperas se reproduce la vida y muerte del día, como señalan los textos correspondientes a cada hora. A Prima, Jam lucis orto sidere. A Completas, Te lucis ante terminum. La música que ennoblece estas palabras está indisolublemente vinculada al transcurso del tiempo y al valor emocional que éste tiene para el hombre. Por tanto, esta música le ayudará a apreciar más la calidad que la longitud del tiempo21. Para obtener ese resultado los cristianos establecieron una determinada codificación de sus cultos. Son los cultos de una escisión del judaísmo. Conservan,

18 M. Eliade, Tratado de Historia de las Religiones, Ed. Era, México 1972 (1964), pp. 328-330 y 350-357. También, por el mismo autor, El Mito del Eterno Retorno. Arquetipos y Repetición, Alianza Ed., Madrid 1972 (1951), p. 15. Sobre el valor de la repetición como determinante de la estructura de la conciencia medieval véase A. GoUREVITCH, op. cit, p. 100.

19 Algunos Oficios de Semana Santa, por ejemplo, deben realizarse en la oscuridad. Por otra parte, en otros Oficios nocturnos la carestia de la cera obligaba frecuentemente a la penumbra. F. LL. HARRISON, loc, cit., p. 317.

20M. ELIADE, El Chamanismo y las Técnicas Arcaicas del Extasis, Fondo de Cultura Económica, México 1960 (1951).

21 J. Blacking, How Musical is Man?, Faber and Faber, Londres $1976^{2}$ p. 52. Sobre la correlación entre período de tiempo y estado anímico en el hombre medieval véase A. GoUREVITCH, op. cit., p. 99, o C. GAIGNEBET, El Carnaval. Ensayos de mitologia popular, Ed. Alta Fulla 1984 (1974) p. 32. 
pues, muchos de sus elementos característicos. Con el tiempo se convertirán en las formas ${ }^{22}$ que hacia el año 1000 se estaban plasmando en aquellos libros litúrgicos cuyas precisiones sonoras tanto nos interesan. Esas formas aparecen y se desarrollan en dos clases de reuniones: en una se ofrece un sacrificio, con valor, por tanto, sacramental (Misa); en la otra se realiza una lectura ritual o recitación del Libro (Oficio). Siguen la división de los cultos judios que, hasta Tito, tenían sus reuniones en el Templo (con sacrificio) o en la Sinagoga (con lectura) 23 .

La primera aparición completa de una codificación de los ritos de las lecturas diarias aparece ca. 530, en la Regla de San Benito. Desde entonces su ordenamiento ha permanecido invariable en lo sustancial, aunque la nomenclatura y algún otro detalle hayan sido alterados en numerosas ocasiones. Su forma varía también, según el Oficio sea para el clero regular - el monástico, o según cada orden monástica. En general, su distribución es, en el actual ordo romanus:

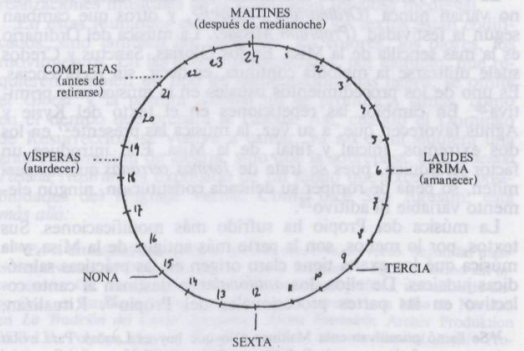

22 J. A. Jungmand, Missarum Solemnia, trad. El Sacrificio de la Misa. Tratado histórico-litúrgico, La Editorial Católica, Madrid 19634. Se entiende que nos referiremos únicamente al ámbito de la Europa Occidental.

23 J. Hani, La Divine Liturgie, Eds. de la Maisnie, París 1981, pp. 53-85. 
Las indicaciones de la Regla ligan cada día ordinario al día astronómico: la hora se prescribe según la posición de los astros y varía con las estaciones. Cada reunión del Oficio comienza con Deus in adiutorium, que se canta con la solemnidad que corresponda a esa hora $\mathbf{y}$ al tiempo anual, $\mathbf{y}$ finaliza con el canto del Benedicamus Domino. Entre estos dos cantos, cada hora tiene su propia organización, aunque se agrupan por sus similitudes estructurales en dos tipos: Horas Mayores (Maitines, Laudes, Visperas, Completas), y Horas Menores (Prima, Tercia, Sexia, Nona). La Hora del Oficio más elaborada con sus propios principios estructurales es Maitines (ad Matutimum). Consta de secciones de apertura y final, más tres nocturnos de estructura semejante entre $s^{24}$. Según el rango del día se permite cierta flexibilidad en su disposición. Esta flexibilidad y la prolijidad admirable de sus melodias es lo que ha hecho de Maitines, junto con los cantos responsoriales de la Misa, la parte de la liturgia más susceptible de reelaboración, variación y modificación musical, como veremos más adelante.

La Misa romana está constituida por unos textos fijos que no varían nunca (Ordinarium Missae)25, y otros que cambian según la festividad (Proprium Missae). La música del Ordinario es la más sencilla de la Misa. En los Glorias, Sanctus y Credos suele utilizarse la melodía continua, es decir, sin recurrencias. Es uno de los procedimientos usuales en la música más primitiva $^{26}$. En cambio, las repeticiones en el texto del Kyrie y Agnus favorecen que, a su vez, la música las presente 27 en los dos extremos, inicial y final, de la Misa. Ello introduce un factor jerárquico, pues se trata de formas cerradas que no permiten, so pena de romper su delicada constitución, ningún elemento variable ni aditivo 28 .

La música del Propio ha sufrido más modificaciones. Sus textos, por lo menos, son la parte más antigua de la Misa, y la música que los exalta tiene claro origen en las prácticas salmódicas judaicas. De ellos, los antifonales se destinan al canto colectivo en las partes procesionales del Propio ${ }^{29}$. Ritualizan,

${ }^{24}$ Se llamó primitivamente Maitines a lo que hoy es Laudes. Para evitar engorrosas confusiones seguimos la nomenclatura actual.

25 Kyrie, Gloria, Credo (sólo desde 1014), Sanctus y Agmus Dei.

${ }^{26} \mathrm{~K}$. SACHS, "Primitive and Medieval Music: A Paralleb), Journal of the American Musicological Society, vol. XIII (1956).

27 Véanse, por ejemplo, el Kyrie II o el Agnus I en el Liber Usualis.

$28 \mathrm{~K}$. SACHS, loc. cit.

29 Introito, Offertorium, Communio. 
pues, un desplazamiento de los asistentes. Su estructura alterna el canto de los versículos de un Salmo con una Antífona. Dos estilos literarios y musicales coexistieron así en el seno de la misma pieza: la Antifona, en estilo libre, cantada colectivamente, y el Salmo, con música en recitativo salmódico, predominantemente silábico, cantado por «las dos mitades del coro alternativamenter ${ }^{30}$.

Los cantos responsoriales de la Misa, por su parte, se ejecutan después de cada lectura a modo de expansión lírica y personal. Aqui lo que se alterna es el canto colectivo de un Responsum con los versículos de un Salmo, que realiza el solista en estilo melismático, lo que da lugar a las más elaboradas y ondulantes melodías ${ }^{31}$. Toda la liturgia de las Lecturas - la primitiva Misa de los Catecúmenos - queda así definida por el contraste entre la recitación silábica de las mismas ${ }^{32}$ y los extraordinariamente floridos melismas de los cantos responsoriales que las siguen. Este contraste de conceptos entre la lectura, normativa, de un texto normativo, y su comentario en estilo personal, adornado y libre, es una de las más hermosas realizaciones musicales de la mentalidad religiosa medieval.

En estas reuniones cultuales no sólo los textos están codificados, sino también las imágenes, los colores, los olores, los movimientos. En las épocas penitenciales, por ejemplo, que requieren también un tipo de alimentación más ligero, se omite el Gloria y la palabra Alleluia no se pronuncia jamás, como en el tiempo que prepara la Pascua. Así, cuando el Domingo de Resurrección se vuelve a cantar, ya no es ni siquiera una gran exclamación de alegria, sino que la sobrepasa: este Alleluia Pascha Nostrum es expresión de un júbilo que excede las posibilidades del lenguaje verbal. Como dice San Agustín, está más allá:

${ }^{30}$ En la actualidad solamente el introito conserva un verso. Según las tradiciones diversas, la Doxología alterna con la Antifona o sigue al Salmo sin interrupción. $C f$., por ejemplo, las dos versiones discográficas, actualmente disponibles en establecimientos comerciales, del Introito de la Misa de Navidad en La Tradición del Canto Gregoriano. Maria Einsiedeln, Archiv Produktion 2533 131, Polydor, sf, y en Canto Gregoriano. Misa de Navidad, Archiv Produktion Privilege, 2547 001, Polydor, 1960. Puede consultarse una descripción introductoria en el prólogo de J. Pascher, El Año Litúrgico, La Editorial Católica, Madrid 1965.

31 En la actualidad se cantan con un solo verso.

32 Sobre una sola nota en recto tono, llamada tuba o tenor, salvando las inflexiones que corresponden a la puntuación. 
Qui jubilat, non verba dicit, sed sonus quidam est latitia sine verbis; vox est enim animi diffusi laetitia, quamtum potest, experimentis affectum, non sensum comprehendentis ${ }^{33}$.

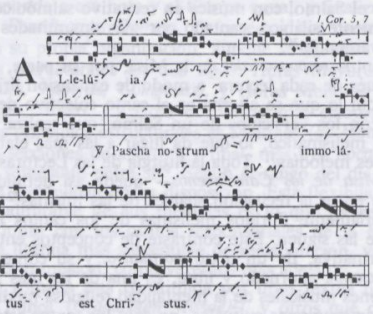

$\mathrm{Y}$ es que las palabras solas dicen:

Alleluia. Alleluia.

v. Pascha nostrum immolatus est Christus Alleluia.

Pero cantadas, en virtud del estilo altamente melismático empleado, se convierten en:

Alleluuuuuuuiaa.

Alleluuuuuuuiaa aaaaaaaaaaaaa aaaaaaaaaaaaaaa aaaaaaaaaaaa v. Pascha noooostruuuuuuuuuuuuuuuum immolaaaaaaaaaaaaaaaaaaaaaaaaaaaaaa aaaaaaaaa aaaaaaatuuuuuuuuuus est Chriiiiiiistuuu unuuuuuuu unuuuuuuuuuuus.

Alleluuuuuuuiaa aaaaaaaaaaaaa aaaaaaaaaaaaaaa aaaaaaaaaaaa.

Es la música lo que ha permitido aquí romper la cárcel del lenguaje y transformar las palabras en un grito sin apenas límites.

${ }^{33}$ S. Aurelii Augustini Enarrationes in Psalmis, 99, 4. PL XXXVII, c. 1272. 
La propia línea melódica estalla al pronunciar por primera vez la palabra Alleluia, tanto tiempo prohibida. Comienza por la nota que determina el modo (sol), e inicia un sinuoso y titubeante movimiento ascendente hasta alcanzar la dominante (re, en la quinta nota de $(\varsigma-\mathrm{lu}-\gg), y$ reitera $(«-$ ia»), dejando el sonido de esa misma dominante como colgado en su brillo y dispuesto para ser ornamentado en el gigantesco melisma del jubilus, que devuelve la melodia a su finalis (sol). El canto actúa asi como una exégesis del texto $^{34}$, de la significación del día, del carácter del tiempo. Es, efectivamente, un icono sonoro.

El transcurso del año, sus diversas épocas, afectan al rito y a su música. Es el año otro ciclo cósmico básico, que reproduce analógicamente la vida del individuo: del Nacimiento (o Concepción) hasta Pascua y Pentecostés, escandida por estas celebraciones esenciales, se desarrolla la vida del Cristo como el drama de la vida humana. A la vez, imita analógicamente la duración de nuestro mundo: todo nuevo año es una creación (ila Creación!); todo fin de año, el fin del mundo ${ }^{35}$. Por eso se lee el relato del fin del mundo tanto en el comienzo como en el fin del año ${ }^{36}$ : individual o escatológicamente, la identidad del origen y del fin supera al tiempo.

Para los medievales, el año estaba dividido en dos ciclos que marchan paralelamente: el Proprium de Tempore (todos los domingos del año siguiendo los hechos de la vida del Cristo), y el Proprium de Sanctis (en que se celebran las conmemoraciones de los Santos en fechas siempre fijas, independientemente del día de la semana que corresponda). Existe una jerarquización que hace prevalecer la fiesta de mayor rango cuando los ciclos coinciden. Un mismo texto litúrgico, según ese rango -0 sea, según el tiempo-, recibirá melodias correspon-

${ }^{34}$ M. SCHNEIDER, «Consideraciones...», El alto grado de coordinación, elaboración y especialización colectiva que exige la ejecución de cantos como éste, no puede lograrse sin estrecha colaboración. Se cumple asi una de las funciones principales de la música en sociedad, socializar. Véase J. BLACKING, op, cir. No es necesario decir que la otra, alienar, también se cumple. La ejecución de melismas de cerca de 50 notas como éstos, puede producir efectos fisiológicos importantes. A. HUXLEY, "Cielo e Infierno", Las Puertas de la Percepción y Cielo e Infierno, Ed. Sudamericana, Buenos Aires 1973, p. 136.

35 J. HaNi, Le Symbolisme..., p. 148.

${ }^{36}$ En el Primer Domingo de Adviento, Le XXI, 25-33; en el último de los Domingos per annum, Mt XXIV, 15-35. 
dientemente más o menos solemnes, más o menos complejas, más o menos adornadas ${ }^{37}$.

El Propio del Tiempo, a su vez, se divide en dos ciclos: el de Navidad, regido por el Sol ${ }^{38}$, y el de Pascua, por la Luna 39 . Los dos ciclos, reproduciendo los ritmos cósmicos, constituyen también una sintesis de los calendarios solar y lunar.

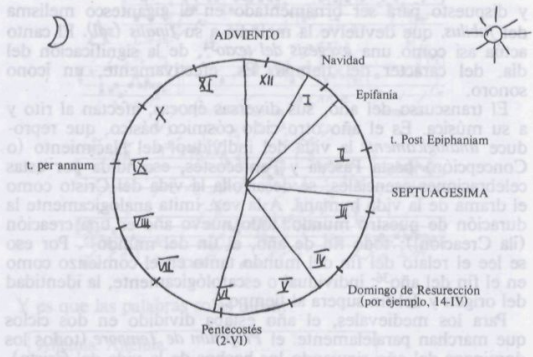

El ciclo de Pascua conserva reminiscencias de calendarios más antiguos aún, habiendo perdido el número correcto de días $^{40}$. Por el contrario, el ciclo solar conserva toda su exactitud: las principales festividades están colocadas en los momentos más señalados del año astronómico, que obedece así a las leyes divinas ( $\mathrm{y}$ no al revés).

${ }^{37}$ Véase, por ejemplo, el gran número de Benedicamus Domino, con sus especificaciones relativas a la ocasión en que se cantan, en el Liber Usualis, o las diversas entonaciones de Salmos del Oficio.

${ }^{38}$ Desde el siglo $\mathrm{V}$, el Nacimiento de Jesús se conmemora oficialmente en las proximidades del Solsticio de Invierno (Navidad).

${ }^{39} \mathrm{El}$ domingo de Resurrección es el domingo que sigue al primer plenilunio de Primavera.

$40 \mathrm{E}$. WERNER, cThe Origin of the Eight Modes of Music (Octoechos). A study in Musical Symbolismy, Hebrew Union College Annual 21 (1948); resumido en Acta Musicologica XX (1948). 
EQUINOCCIO DE OTON̂O 29-IX: Arc. San Miguel

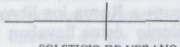

SOLSTICIO DE VERANO

24.VI: San Juan Bautista
EQUINOCCIO DE PRIMAVERA

25-III: Anunciación

El canto sagrado, imitando a estos celestes movimientos e imitado incesantemente a escala microcósmica, estaba profundamente grabado en la vida de sus ejecutantes. Era demasiado precioso para descuidarlo; se transmitía oralmente, ya que no era posible fijarlo por escrito:

Nisi enim ab homine memoria teneantur soni, pereunt, quia scribi non possunt ${ }^{41}$.

La memoria debía, pues, suplir a la escritura. Hacia el año 1000 , el contenido de los primeros libros litúrgicos con música liberaba de ese esfuerzo a los cantores, y al ser escrita adquiría estatus canónico, o sea, el carácter de autoridad. Por esas mismas fechas, el repertorio ${ }^{42}$, con más o menos variantes, se estabilizaba en su forma más duradera.

Estos libros provienen todos del norte de Europa, Reichenau, St. Gall, Chartres. Ninguno está escrito en Italia. Sin embargo, el repertorio no era en su totalidad fruto del espíritu otónida, ni tan siquiera del carolingio. En realidad, en la se-. gunda mitad el siglo VII, la situación habia sido la contraria: eran Pipino y Carlomagno quienes importaban los libros de Roma. Incluso llegaron a abolir su propio rito cambiándolo por el romano. Y sucedió que los libros traídos de Roma eran Sacramentarios, es decir, que contenian los textos que se debian formular los días muy solemnes, cuando oficiaba el mismo Papa. Para ser útiles, debian completarse hasta cubrir el ciclo anual íntegro. Esta fue la tarea encomendada a Alcuino

${ }^{41}$ SAN IsIdoro DE SEVILlA, Etimologias, Ed, de J. Oroz, M-A. Marcos y M. C. Diaz, La Editorial Católica, Madrid 1982, p. 442. Cf. L. Tremter, "Oral, written and literate process in the transmission of medieval music», Speculum 56 (1981).

42 L. TRFITLE, loc, cit. 
de York, que, por lo que parece ${ }^{43}$, incorporó elementos genuinamente francos para ello. Por tanto, cuando las circunstancias políticas hacian «regresar» a Roma los libros, en los años cercanos al cambio de milenio éstos llevaban ya el injerto de las costumbres rituales francas, distinguidas por su magnificencia y esplendor. Esta es la razón de que a su contenido se le denomine (el ritual romano-franco $) 44$.

A su vez, tampoco la parte romana que Alcuino habia utilizado era auténticamente romana en su totalidad. Los ritos papales, en los primeros siglos del Cristianismo, eran más bien orientales y en lengua griega. Estaban muy diferenciados de los que se realizaban más al norte y en Occidente. Los estudiosos los agrupan en la gran familia llamada «ritual romanoafricano ${ }^{45}$. La otra familia correspondiente a ésta es la llamada "galicana», que incluye, en realidad, el propio ritual de las Galias (galicano o merovingio), el celta, el hispano, el milanés, etc. Conviene no olvidar que, dejando aparte los ritos propios de las diferentes órdenes monásticas, el número de liturgias cristianas antes del Concilio de Trento se aproxima a la veintena $^{46}$. Siendo una misma religión, la plasticidad de sus ritos les permite adaptarse a las diferencias nacionales, del mismo modo que hoy dia sucede, por ejemplo, con la música budista, la cual, en Tíbet o en Japón, presenta grandes diferencias.

La tradición dice que quien estableció una forma propia y reformada para el ritual romano fue Gregorio I (590-604), aunque no hay documentación que lo pruebe. Es una tradición originada muchos años después. No es fácil, por tanto, saber cómo se llevó a cabo su re-organización, pero si es posible seguir las fases de su difusión. Gregorio utilizó a los monjes benedictinos, bajo la responsabilidad de Agustín de Canterbury, para evangelizar a los sajones y anglos del este de la actual Inglaterra. Con ellos, el rito romano-gregoriano reemplazó al celta-irlandés, qủe se habia originado en las instituciones monásticas fundadas por San Patricio en el siglo v, y del que no queda absolutamente nada de música, y sólo algunos fragmentos de textos. Cuando en los siglos VI y VII los monjes irlandeses, por su parte, se lanzan a evangelizar

43 J. A. JUNGMANN, op, cit., pp. 98-117.

44 Algunos estudiosos modernos niegan el carácter romano del canto gregoriano. Véase un estado de la cuestión en P. F. CUTTER, «The Cuestion of the "old-Roman" Chant: A Reappraisal", Acta Musicologica XXXIX (1967).

$45 \mathrm{~J}$. A. JUNGMANN, op. cit., pp, 65-71.

$46 \mathrm{~F}$. LL. HARRISON, loc, cit. 
Europa, yendo hacia el este, el ritual que llevan es el romanogregoriano.

Así pues, cuando por vez primera se realizan esos manuscritos que llevan, además de las palabras sagradas, la música que las hace más eficaces, su contenido es el reflejo exacto de los avatares históricos por los que había pasado Europa occidental durante el primer milenio ${ }^{47}$. Pero cuando nos dirigimos a estos primeros libros, vemos que sus delicadas precisiones no son legibles para nosotros: utilizan una notación que nos permite saber cuántos sonidos corresponden a una sílaba del texto, si son agudos o graves, y sus detalles rítmicos y expresivos, pero no la entonación exacta. Los signos que emplean, neumas, derivan de los gramaticales. Corresponden a un tipo de pensamiento musical más bien prosódico. No es de extrañar, por tanto, que tampoco estos neumas indiquen una medida matemática del tiempo, y que ni siquiera lo pretendieran. «Neumae sine lineae, sicut puteus sine fune»" 48 . Se trata de una notación cualitativa. No es, por cierto, la única: en las mismas fechas se tantean otros procedimientos que parecen buscar lo que ella lograba, es decir, normalizar el rito y aliviar la memoria. Pero son las diferentes notaciones neumáticas las que prevalecerán. Como en todas las notaciones musicales - a excepción de algunas contemporáneas - el ejecutante las completa en el momento de la interpretación. El elevado grado de flexibilidad que posee la notación neumática permite atribuir gran importancia a la improvisación en el resultado sonoro final.

También hay textos que no llevan notación alguna porque se cantaban en los diversos recitativos, que son, como los toni psalmorum, unas fórmulas musicales adaptables a frases de diferentes longitudes. Aparte los Salmos, la cuerda de recitación solia ser sobre la nota la, es decir, a distancia de un tono entero de la «sensible», si se nos permite este término. Hacia

${ }^{47}$ Hasta la unificación de Trento las diferencias nacionales no fueron totalmente eliminadas. La alusión al primer milenio señala la difusión y estabilización de la Misa franco-romana. Véase J. A. JUNGMANN, op. cit., pp. 118-124. Quedarán, con todo, usos y costumbres locales; por ejemplo, el llamado "canto visigótico".

${ }^{48} \mathrm{La}$ melodia ha sido restituida por comparación con los manuscritos diastemáticos posteriores, tal como aparece en la Editio Vaticana. Sobre los aspectos ritmicos y la interpretación, véase C. AuGustonl, Le Chant Grégorien. Mot et neume. Herder, Roma 1969 (1963), y Dom E. CARDINE, Semiologie Grégorienne, extrait des Etudes Grégoriennes XI (1970). 
el siglo XII se aprecia una tendencia a recitar en las notas inmediatamente superiores a un semitono, es decir, en $f a$ y en do, lo que da tonos más brillantes

porque reducen la plenitud de las funciones musicales a dos polos, dejando en la sombra todo el fiel y abnegado séquito de las subdominantes. Son brillantes porque son pobres. Por el contrario... [en] los modos sol, re, la, mi, la tendencia a las dominantes está refrendada por el contrapeso de los movimientos de subdominantes ${ }^{49}$.

Así empezó a resquebrajarse el círculo de quintas, a convertírse en un óvalo; con la recitación a distancía de un semitono del grado inferior, se abre el camino hacia la tonalidad funcional moderna, olvidando la organización melódica del gregoriano, que es aditiva, no funcional ${ }^{50}$. No es casualidad, por tanto, que la aparición de la tonalidad moderna coincidiera con la concentración de todos los modos en sólo los más cercanamente similares a nuestros Mayor y Menor $^{51}$, en los que recitan en do y en $f a$.

Las melodias para los textos no recitados son cantos más bien rapsódicos o melismáticos, en los que las sílabas de una palabra llevan varias notas. Se agrupan en ocho modos, como Jos tonos de Salmos. Estos modos son octavas que se caracterizan por la diferente distribución de los tonos y semitonos con respecto a la nota dominante y a la final, o sea, ámbitos o tesituras de diferente capacidad expresiva. La codificación de los modos en ocho es obra del siglo $\mathrm{x}$, es decir, de un momento en que la mayor parte del repertorio gregoriano ya existía. Se cree que muchas melodías fueron forzadas para hacerlas coincidir con el esquema de los modos ${ }^{52}$. Nada simboliza mejor la

49 M. SCHNEIDER, "Consideraciones...».

$50 \mathrm{~K}$. SACHS, loc. cit. En este sentido, la moderna tonalidad actúa como la perspectiva en pintura: unifica e interrelaciona todos los puntos del respacio sonoro" en torno a un centro jerárquico único. E. E. LOWINSKY, “The concept of phisical and musical space in the Renaissancen, Papers of the Musicological Society 57 (1941), y E. PANOFSKY, La perspectiva como uforma simbólican, Tusquets Ed., Barcelona 1973.

51 W. APEL, Gregorian Chant, Indiana University Press, Bloomington 1958, p. 204. El elemento decisivo no es la nota final, sino la de recitación, p. 210. El Liber Usualis ofrece varios Toni Antiquiores que recitan en la.

52 Ya existía una cierta sistematización en los llamados Tonarios y en ciertas melodias clasificadas según su fórmula melódica inicial. Aun así, 
visión medieval del mundo que esta heterogénea modalidad, frente a la «dinámica, explosiva tonalidad» 33 . El positivismo terrestre, la sobrestimación de las posibilidades personales, la mitificación de la propia voluntad, del propio poder y de la fe en un progreso continuo e ilimitado, es lo que acentuará los «movimientos ascendentes de las tonalidades $)^{54}$, es decir, de las dominantes, $y$, con ellas, de la tonalidad funcional.

La existencia de los ocho modos la explican los teóricos medievales apelando a la autoridad del sistema griego transmitido con ciertas dificultades por Boecio, o al movimiento planetario, como reminiscencia del tema pitagórico-platónico de la Armonía de las Esferas, o a las ocho notas en que está dividida una octava $^{55}$. Los teóricos modernos tienden más a relacionarla con los ocho modos del Octoechos bizantino, que no es, hablando con propiedad, un sistema de clasificación de las melodías, sino una colección de fórmulas, de entre las que se escogen las necesarias y se combinan según sus propios significados, es decir, según el rango del día, la ocasión, el texto, etc. ${ }^{56}$. Su origen se halla en la práctica de cantar en cada ciclo de 50 dias ( 7 semanas de 7 días, más un día) los textos correspondientes con la música, siguiendo el orden de sucesión modal en cada domingo, hasta ocho, tal y como aún hoy día lo conserva la Iglesia Nestoriana ${ }^{57}$, y como los especialistas en canto bizantino habian ya observado:

El año eclesiástico sirio comienza con el primer domingo de Noviembre, y camina en ciclos de ocho domingos, en los cuales, los cantos del Octoechos son cantados en su orden de sucesión modal; esta costumbre se extendió de Siria Occidental al Imperio Bizantino ${ }^{58}$.

cerca del $1 \%$ del repertorio actual permanece en ambigiedad modal. W. APEL, op. cit., pp. 166-178.

53 E. E. LowINSKY, Tonality and Atonality in Sixteenth-Century Music, University of California Press, Berkeley and Los Angeles 1961, p. 61.

34 M. SCHNEIDER, «Consideraciones...».

55 E. WERNER, loc. cit.

56 E. Werner, loc. cit. El Canto Gregoriano utilizó la composición musical por adición de fórmulas en algunas melodias que todavia se conservan. Se les da el nombre de centonizadas. W. APEL, op. cit., p. 246.

57 E. WERNER, loc, cit.

58 E. WELLESz, Aufgaben un Probleme auf dem Gebiet der orientalischen und byzantinischen Kirchenmusik, Muenster 1923, p. 101, citado en E. WERNER. loc. cit. Posteriormente, el mismo E. WELLESz reconfirmaria la teoría de Werner, A History of Byzantine Music and Himnography. Oxford University Press $1961^{2}$, pp. 67-70. 
El principio de los ocho modos, común a la música griega clásica, a la medieval, hebrea, árabe y siria, «es uno de los más antiguos intentos del hombre por organizar el caos» ${ }^{59}$; muestra la íntima relación entre música, liturgia, calendario y especulación cosmológica. Algo de esto hubo también en Occidente, puesto que se llega a explicar de modo similar la elección del número ocho para el de modos melódicos: «quod autem octo sint coelestes motus videntur imitari» ${ }^{60}$.

Todos estos secretos y misterios eran el contenido de aquellos libros copiados en los siglos IX y X. El Graduale custodiaría los cantos de la Misa, el Antiphonale, los del Oficio. Hubo otros libros más especializados: Kyriale, Vesperale, Processionale, Sacramentarium, Lectionarium, según la antigua tradición de agrupar en un libro lo que corresponde a cada función litúrgica. Cada uno de estos libros está destinado al obispo, o al celebrante, o al diácono o lector, etc. Por ejemplo, el Cantatorium contiene únicamente los cantos responsoriales de la Misa destinados al solista. Y así los restantes. Pero la práctica ha determinado que se polarizaran en aquellos dos, que síguen otro criterio en la determinación de su contenido.

Y una vez constituidos Gradual y Antifonario, iqué podia hacerse sino conservarlos con temor y veneración? El canto gregoriano, así recogido y ordenado, subrayando la diversidad de los tiempos, protegiendo en los ritos de paso, acompañando en los ritos de la desolación, excitando en los ritos gozosos, fue considerado como un todo integral, sacrosanto, inalterable ${ }^{61}$. Resultado y producto de muchos espíritus, de muchos siglos y generaciones, se hallaba purificado de todo lo extravagante, insuficiente y perturbador de la experiencía individual.

59 E. WERNER, loc. cit.

60 Aurelianus Reomensis, «Musica Disciplina», en M. Gerbert, Scriptores Ecclesiastici de Musica Sacra potissimum, Saint Blasien 1784 (reimpr. Milán (931), vol. I, p. 40. Prevalecerá, sin embargo, la consideración de los modos como un "surtido" de material sonoro del que pueden extraerse a voluntad las notas escogidas. Con ello se invierte la operación, pues ninguna melodía deriva de ninguna construcción intelectual como son los modos, sino que son éstos los que se deducen de ellas. K. SACHS, loc. cit. De hecho tales modos existen sólo a posteriori en los teóricos. E, WERNER, loc. cit.

61 M. BUKOFZER, "Speculative Thinking in Mediaeval Music", Speculum XVII (1942) y L. TREITLER "Centonate" chant: Ubles Flickwerk or E pluribus umus? , Journal of the American Musicological Society 28 (1979). L. AugusTONI, op. cit, pp. 28-29. 
$\mathrm{Y}$ al ser revelado resultaba inescrutable a la mente humana ${ }^{62}$. Representa, pues, una totalidad irracional y protege de su contacto inmediato: es un dogma ${ }^{63}$.

\section{TENOR}

Como en todo lo que es propiamente tradicional, el dogma equidista de la objetividad de la experiencia y de la subjetividad del individuo que experimenta. Esto es lo que le concede un especial valor: su privilegiada situación en el punto exacto entre lo colectivo y lo individual. Por lo mismo, es lo que le otorga ese carácter impersonal y «no humano» que lo hace permanente e inmutable, contrapesado por lo contingente de cada formulación. Y es lo que hace a una tradición susceptible de adaptaciones, reformulaciones o modificaciones, condicionadas por un elemento o circunstancia concreta. Bajo esas modificaciones, la permanencia está siempre asegurada, al menos en lo que concierne a lo esencial ${ }^{64}$.

El repertorio gregoriano era expresión viva del conjunto de experiencias religiosas de los hombres que vivieron en los años anteriores al 1000. La existencia de esta tradición no fue un freno para actuaciones individuales. Se prestaba a recibir aportaciones personales, contribuciones ocasionales - lo que llamamos ahora creatividad-, gracias a su flexibilidad. Ese proceso creativo se realizaba apoyándose en lo que ya existía: los medievales canalizaron su creatividad, la basaron en el único repertorio orgánico que conocian, el gregoriano. Es para ellos su punto de referencia inmutable. Esta nueva actividad ya no tendrá el carácter de dogmática. Proviene de intervenciones individuales, subsidiarias. No tocan el repertorio básico; lo completan o lo expanden, a veces lo interpolan, pero lo que hacen siempre es comentarlo, glosarlo. Lo rodean sin llegar a tocarlo, porque el impulso creativo es $\tan$ fuerte en la Edad Media como en cualquier otra época. Así, entre el temor y el amor, entre la veneración respetuosa y el ímpetu creativo, se desarrolla, particularmente en los siglos $\mathrm{X}, \mathrm{XI}$

${ }^{62}$ N. PIRrotTa. "Dante musicus: Gothicism, Scholasticism, and Music», Speculum 43 (1968).

${ }^{63} \mathrm{En}$ el sentido que da a este término C. G. JUNG, Psicologia y Religión, Paidós. Barcelona 1937, pp. 78-84.

${ }_{64}^{6}$ R. GUÉNON, (Tradition et transmission), Aperçus sur linitiation, Ed. corrigée, Eds. Traditionnelles, Paris 1980, pp. 61-64. 
y XII, una gran actividad en torno $a$ el rito oficialmente establecido. De este modo es como se mantiene el equilibrio entre lo viejo y lo nuevo, entre lo establecido y lo inventado, entre la auctoritas y el individuo ${ }^{65}$.

La creatividad individual podia, por ejemplo, ejercerse en la composición de los cultos de las muchas festividades nuevas que inventó la Edad Media: Trinidad (siglo X), Corpus Christi (siglo XIII), fiestas marianas, fiestas dedicadas a los nuevos santos y a sus milagros, al patrón del lugar, o para las cruzadas y peregrinaciones, etc. También en los llamados tropos.

Tropar es añadir a un canto nueva música, nuevas palabras, o ambas cosas a la vez ${ }^{66}$. Los tropos, por tanto, no son obras autónomas: separados de la obra a la que adornan pierden su razón de ser y se convierten en incomprensibles y fragmentarios (salvo un caso que veremos después). En cambio, el canto originario, desprovisto de ellos, conserva toda su integridad y sentido. Los centros principales de donde provienen la mayor parte de estos añadidos son los monasterios de Saint Gall y Saint Martial de Limoges; pero debió haber otros. Saint Gall y Saint Martial se han destacado siempre por su pericia y fortuna en la conservación de las antiguas bibliotecas. Sus nombres nos sirven más bien para señalar los límites geográficos de la primitiva actividad de re-elaboración. Esta actividad está documentada desde el siglo IX. La cronología se aproxima, pues, a la de la copia de los libros con notación musical, porque las dos actividades responden al mismo impulso de solemnizar el acto ritual. Los troparios, libros que contenian el conjunto de adornos añadidos, eran también muy venerados ${ }^{67}$.

Tanto la Misa como el Oficio pueden presentar tropos, aunque con características propias en cada caso: es el sentido de la obra el que determina el carácter del tropo. En la Misa, los lugares preferidos suelen ser los ritos de entrada y despedida (más tarde, alguna de las lecturas); en el Oficio, el Benedi-

${ }^{65} \mathrm{M}$. BUKOFZER, loc, cit.

${ }^{66} \mathrm{En}$ las fuentes medievales el término tiene un sentido más restringido, y, a la vez, puede significar otras cosas. Pero sin utilizarlo en latín (tropus), se considera correcto cuando se refiere al fenómeno en general. El repertorio de tropos fue prohibido en Trento, $y$ la Restauración Gregoriana, por razones obvias, solamente nos ha restituido la parte oficialmente sancionada del ritual.

67 J. HandsCHIN, «The two Winchester tropers", The Journal of Theological Studies 37 (1936). 
camus Domino, final de todas las Horas, o las Horas más brillantes: Visperas (en el Responsorio) y Maitines (después del último Responsorio del tercer Nocturno, o al final de cada Nocturno). El tropo se convierte así en el pórtico solemne del rito, que señala la importancia de la celebración por medio de su propia presencia. A lo largo del año las festividades resaltan con el brillo de unos actos más decorados y más prolijos.

$\mathrm{La}$ forma en que opera un tropo puede variar: en unos casos se intercalan nuevas melodias; en otros un nuevo texto en una vocalización melismática; en otros se añaden ambas cosas. Unas veces se intercalan; otras, sustituyen secciones del canto original ${ }^{68}$. Pero estos tipos diferentes no implican un desarrollo cronológico. Tampoco una ruptura del equilibrio entre el canto original y el tropo, aun en los casos en que la dimensión del tropo excede a la del canto original. En este caso el resultado es una obra nueva con citas de autoridad, como referencia siempre presente y garantia de su autenticidad.

En el primer tipo (Hlamado neuma o melodía), el carácter del canto tropado no cambia, pues su texto se conserva íntegro, sólo que con vocalizaciones más largas. Los fragmentos melódicos intercalados pueden ser originales o extraídos de otro canto ${ }^{69}$. En las fuentes, el canto original suele aparecer sin apenas variantes, siendo, en cambio, abundantes en el tropo. El tratamiento de lo individual, como se ve, es más libre; el canto original no admite variaciones.

Cuando lo que se añade es un nuevo texto, sin tocar la música, el tropo se denomina prosa o prosula. Desde el punto de vista musical, esto significa que una melodía melismática se transforma en silábica, perdiendo probablemente su ritmo prosódico. Desde el punto de vista del texto, significa que debe elaborarse de tal modo que conserve la lógica gramatical, acomodando el número de sus sílabas al de notas disponibles en el melisma musical. Esta última condición no parece cumplirse siempre en los cantos responsoriales, los más melismáticos, los más adecuados para este tipo de tropo. Parece más

68 Entre otras clasificaciones de los tipos de tropos, seguimos ésta: R. WEAKLAND. "The beginnings of troping», Musical Quarteriy 44 (1958). Cf. J. Chailley, L'Ecole Musicale de Saint Martial de Limoges jusqu'a la fin du XI siècle, Les Livres Essentiels, Paris 1960.

69 Existen enteros "Melismas migratorios», por ejemplo, W. APEL, op. cit., p. 343. Para los siguientes párrafos nos basamos en R. HoppIN. Medieval Music, Norton, Nueva York 1978. 
bien que lo que se busca es la asonancia, colocando palabras cuyas vocales coinciden con las del melisma tropado: "Predomina el sonido sobre el sentidos ${ }^{70}$. Por el contrario, cuando lo que se añade es texto y música a la vez (tropus en las fuentes), no hay cambio de estilo en el canto tropado.

Pero hay un tropo que llega a desprenderse del canto que lo origina: se trata de la llamada secuencia, que primeramente era un tropo de Alleluia de la Misa, uno de los cantos responsoriales más melismáticos. Notker Balbulus relata en la introducción a su libro de secuencias que estando en Saint Gall encontraba dificultad en recordar los largos melismas de los cantos responsoriales. Un día llegó al monasterio un monje de Jumièges, que huía de los normandos $(862)$. Llevaba consigo un objeto precioso: un Antifonario. En él, las melodías de los Aleluyas se habían rellenado con nuevos textos. Notker nos dice que encontró en ello un alivio para su falta de memoria: con el texto completo le era (es) más fácil recordar la música. Esto le indujo a componer él también nuevos textos para las temidas melodías responsoriales. Se conservan esos textos, pero sin la música. Como Notker no descuidó indicar a qué cantos corresponden, han sido reconstruidas reuniendo antiguos manuscritos que los contienen ${ }^{71}$.

Las melodías de las secuencias, como las de todos los tropos, eran susceptibles de modificación. A veces aparecen con títulos que no corresponden al incipit del texto, como es costumbre: esto podría indicar que se trata de melodías con vida propia. Suelen tener una estructura repetitiva, llamada incluso «estrofa» ${ }^{72}$, que reaparecerá después en el lai francés y leich germánico. Esto, unido al carácter individual del texto y al hecho de que existen algunas secuencias en las fuentes francesas con textos parciales, las relaciona con el mundo secular ${ }^{73}$. Sin embargo, parece que se trata de una creación especifica del genio franco-occidental como alternativa a las peculiaridades melismáticas y más orientalizantes del recientemente impuesto canto romano ${ }^{74}$. Por ejemplo, el hecho de que la es-

${ }^{70}$ R. H. HOPPIN, op. cit., p. 149.

71 Véase R. L. CROCKER, «The Early Frankish Sequence: A new musical formy, Viator 6 (1975), de donde procede el ejemplo siguiente. Sobre el tema, la obra de consulta es: R. L. CROCKER, The Earby Medieval Sequence, Berkeley 1977.

72 R. L. CROCKER, loc. cit.

${ }^{73}$ R. H. HoppIn, op. cit., pp. 161-162. También se las relaciona con el contraste melismático/silábico. J. HANDSCHIN, loc. cit.

74 R. L. CROCKER, loc. cit. 
tructura formal no sea continua, sino con repeticiones paralelísticas, o la tendencia al silabismo, son elementos contradictorios o alternativos con las agotadoras vocalizaciones de los cantos responsoriales romanos.

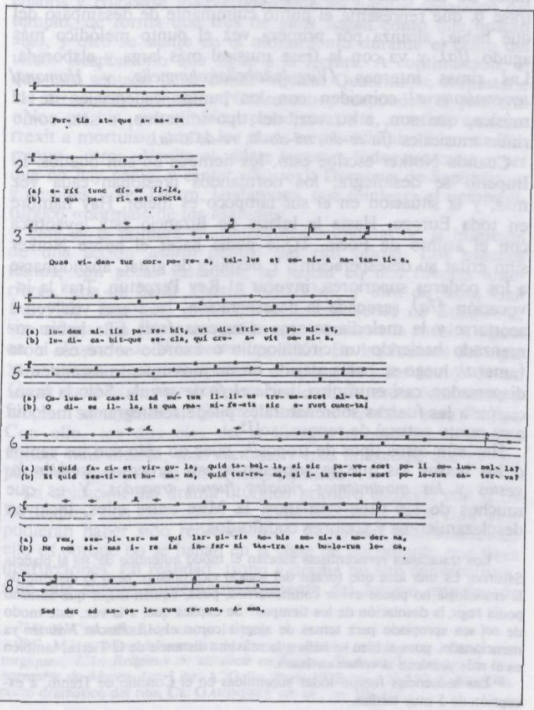


En este ejemplo se puede ver un caso típico: las «estrofas» de dos versos son introducidas por sendas frases simples, sin repetición. La música se pliega a esta disposición del texto, puesto que es silábica: la progresión dramática del contenido hacia las frases $6 a$ y $6 b$ es paralela a la progresión en las longitudes de las frases musicales y en el ámbito melódico. La frase 6 , que representa el punto culminante de desamparo del que habla, alcanza por primera vez el punto melódico más agudo (fa) y va con la frase musical más larga y elaborada. Las rimas internas (Virgula/tabella/columnella, y Humana) terrena/caterva) coinciden con los puntos cadenciales de la música, que son, a su vez, del tipo imitativo, o sea, como rimas musicales (fa-re-do, mi-do-la, re-dósi-la).

Cuando Notker escribe esto, los tiempos no son buenos. El Imperio se desintegra, los normandos presionan cada vez más, y la situación en el sur tampoco es mejor. Hay hambre en toda Europa. Hasta la Iglesia de Bizancio está levantisca con el asunto de Focio. ¿Qué podía hacer el pobre Notker sino gritar su desesperación? Y después de gritar, abandonarse a los poderes superiores, invocar al Rey Perpetuo. Tras la in vocación (7a), serenada la desesperación, las frases vuelven a acortarse y la melodía retorna a su casa (sol). Ella había comenzado haciendo un circunloquio o exordio sobre esa nota (amara); luego se había alejado en un movimiento ascendente, dispersador, casi entrópico, hacia el fa de virgula. Sólo la invocación a las fuerzas sobrenaturales puede reintegrar la melodía a su punto natural de reposo, sol 75 .

Hay aún otros tipos de tropos $^{76}$, pues no sólo son los cantos - los textos los que se someten a este proceso: también los gestos y los movimientos rituales fueron tropados. Y es que muchos de los ritos cristianos, la Misa entre ellos, incluyen desplazamientos y acciones codificados.

${ }^{75}$ Los tratadistas renacentistas asocian el modo auténtico de sol al planeta Saturno. Es una idea que toman del legado ciceroniano, pero lo distante de la cronología no puede evitar conmovernos, pues, ¿quién mejor que Saturno podia regir la desolación de los tiempos? Se explica que, a la vez, este modo de sol sea apropiado para temas de alegria como el All. Pascha Nostrum ya mencionado, pues si bien se halla a la máxima distancia de la Tierra, también es el más próximo al cellum stellatum.

${ }^{76}$ Las secuencias fueron todas suprimidas en el Concilio de Trento, a excepción de 5 muy tardías. 
En 965-975 d. JC., Ethelwold, obispo de Winchester, escribe una Regularis Concordia. Quiere dar las más precisas indicaciones para la correcta celebración del rito. Por eso, sus instrucciones son minuciosas. Cuando habla de los Maitines de Pascua explica cómo durante la tercera lectura del último Nocturno varios hermanos deben vestirse con los trajes adecuados y colocarse inadvertidamente en lugares señalados del templo, de forma que tres de ellos hagan como que buscan algo, $y$ otro se siente en el monumento durante el canto del tercer Responsorio que sigue a la lectura. A continuación, el que está sentado debe cantar «Quem Quaeritis?»; contestarle los otros tres: "Ihesum Nazarenum»; responder el primero: «Non est hic, surrexit sicut praedixerat. Ite, nuntiate quia surrexit a mortuis»); cantar los otros tres: «Alleluia, Surrexit Dominus»; otro: "Venite el videte locum»; todos acercarse y ver que no hay nadie, $y$ cantar «Surrexit Dominus de Sepulchro»; y después, «Te, Deum, laudamus», que reintegra al tiempo litúrgico «normal» de los Maitines ${ }^{77}$.

Esta es la primera constatación documental de la inserción de una acción teatral dentro del rito oficial. Los mismos textos, con pocas variantes, se hallan en dos fuentes anteriores, una de Saint Martial (923-934), y otra de Saint Gall (ca. 950). Los dos, como en las instrucciones de Ethelwold, sin música. La primera versión que conserva la música figura en el Tropario de Winchester (ca. 980). En las fuentes del siglo $\mathrm{XI}$ comienzan luego a aparecer la mención y los textos de un Quem quaeritis in praesepe para Navidad, de estructura, texto y función semejantes al Quem quaeritis in sepulchro para Pascua. Con ello, los dos ejes de la liturgia se adornan con más textos, más música, más acciones y más imágenes, que pronto pasan al repertorio de los artistas plásticos ${ }^{78}$.

La ubicación del drama litúrgico primero coincide con la de los tropos. Los dos textos de Saint Martial y Saint Gall bien pudieran haber sido representados. Si no hay indicaciones de ello es porque no se hallan en la clase de documento que lleva instrucciones. En realidad, tropo y drama no son consecutivos, sino que surgen contemporáneamente del mismo impulso de

77 E. K. CHAMBers, op. cit., p. 14 y ss.

${ }^{78}$ E. MALE, cEnrichissement de l'iconographie: La liturgie et le drame liturgiquen, L'Art Religieux du XII siècle en France. Etude sur les origines de l'iconographie du Moyen Age. Libr. A. Colin, Paris 1922, pp. 121-150. Sobre el aspecto dramático del rito, CL. GAIGNEBET, op. cit., pp. 106-107. 
amplificar y adornar las acciones litúrgicas, música incluida. Las referencias a la dramatización pronto son habituales en los libros de costumbres rituales. El drama se ampliará con nuevos episodios en la corte de Herodes, o la Matanza de los Inocentes, Reyes Magos, vidas y milagros de santos etc. Siempre son en latín $y$ dentro del templo. A finales del siglo XIII y comienzos del XIV aparecen las menciones a los dramas en las diversas lenguas vernáculas. Son siempre fuera del templo. Igualmente llegarán a aparecer referencias a la danza sagrada: la obra de arte litúrgica se enriquece cada vez más.

Los textos de los dramas latinos pueden ser únicamente litúrgicos, conservando en este caso su propia melodia. Cuando no son litúrgicos, son poéticos, con una sola forma de versificación. Se les puede aplicar, a semejanza de lo que se cree que se hacía con las canciones de gesta, la misma melodia a cada estrofa. Pero lo más frecuente es la alternancia de textos litúrgicos y textos nuevos, con sus respectivas melodias gregoriana y nueva. Se crea así un delicioso contraste entre la poesía rimada, para los momentos líricos, los diálogos en prosa, y los textos litúrgicos como referencia inamovible ${ }^{79}$. Estos últimos no pueden faltar porque son los que dan sentido a todos los demás. Aseguran la corrección y continuidad del rito, y por eso mismo la unidad de la obra.

Otro tropo que aumenta la solemnidad y eficacia del rito medieval es lo que llamamos la polifonia, es decir, el sonido simultáneo de varias melodias. Una de ellas será gregoriana, la o las restantes nuevas. La voz que canta el gregoriano, la que proclama el dogma, inalterada, se llegará a llamar tenor, porque es la-que-tiene; las voces añadidas, inventadas, recibirán diferentes nombres según la época y serán tratadas con las libertades correspondientes. Puesto que la polifonia es un tropo vertical $^{80}$, no se le debe el mismo respeto cauteloso que al canto originario.

${ }^{79}$ Es una estructura que permanece en la música occidental. Por ejemplo, aparece en algunas formas vocales barrocas que alternan recitativo (narración y/o contenido doctrinal) y aria (efusión lirica correlativa). De hecho, P.H. Lang llega a llamar tropo a ciertos recitativos de los siglos XVII y XVII. P.H. LANG La Música en la Civilización Occidental, Eudeba, Buenos Aires 1963 (1941), p. 829. Postura contraria en R. WALLACE, "The role of music in liturgical drama: A revaluationm, Music and Letters 65 (1984).

$80 \mathrm{M}$. BUKOFZER, loc. cit. 
El hecho de que la música europea posterior no haya retornado jamás a su etapa monódica, ha ocasionado que se considerara a la polifonía como algo distinto, específicamente europeo y exclusivamente musical. Así será, pero no hasta el siglo XIII: el canto polifónico existe en las culturas primitivas. Como no está sistematizado rígidamente recibe el nombre de heterofonia ${ }^{81}$. En San Agustín, en Boecio y en otros, puede documentarse la consciencia de la practicabilidad de los sonidos simultáneos ${ }^{82}$. De hecho se produce automáticamente cuando cantan personas de diferentes tesituras vocales: hombres y mujeres, hombres y niños, etc. Lo peculiar de la polifonia medieval europea es, en primer lugar, su progresiva tendencia a la sistematización y racionalización; y, en segundo lugar, su corrimiento posterior hacia la armonía funcional.

Pero antes de todo eso, tenía la misma significación que los tropos. Lo dicen los teóricos carolingios: el canto polifónico se hace «pro ornatu ecclesiasticorum carminum» ${ }^{83}$. Precisamente porque el canto polifónico estaba dirigido al mismo objetivo que el canto tropado, ornare, lo vemos florecer en las mismas áreas geográficas y cronológicas que el tropo y el drama. Y porque era igualmente un ornamentum, lo encontramos fijado en las mismas fuentes, en libros que contienen grandes repertorios de adornos al rito, como son los Troparios de Winchester: la polifonía hacía por superposición lo que los tropos hacian por interposición ${ }^{84}$.

Sin embargo, lo cierto es que, efectivamente, en la polifonía hay algo más: se oye a la vez el tropo y el canto tropado. Se introduce con ello un elemento de sincronicidad temporal, que le otorga un sentido especialmente místico ${ }^{85}$. Es asi como esos mismos escritores carolingios lo entendian. Para Scotus Erigena, por ejemplo, «Armonia interpretatur adunatis dissimilium, videlicet, vocum ratis proportionibus conjunctarum ${ }^{86}$,

Coniunctio dissimilium es, pues, la función del canto a varias $\operatorname{voces}^{87}$, unir los contrarios, la función mística por excelencia.

${ }^{81} \mathrm{~K}$. SACHS, loc. cit.

${ }^{82}$ R. H. HoppIN, op. cit., p. 188.

${ }^{83}$ Musica Enchiriadis, M. GERBERT, op. cit., p. 171.

$84 \mathrm{~J}$. HANDSCHIN, loc cil.

85 M. SCHNEIDER, El Origen Musical..., pp. 3-4. Sobre el principio de sincronicidad, C. G. JuNG, El Secreto de la Flor de Oro, Paidós, Barcelona 1981. p. 16.

$86 \mathrm{~J}$. SCOTUS ERIGENA. Annotationes in Martiamum, en P. JONES, The Glosses De Musica of John Scottus Eriugena in the Ms. Lat. 12960 of the Bibliotheque Nationale, Roma 1957, p. 36.

${ }^{87}$ Los teóricos de la música rozan continuamente la expresión. Por 
Pero esa unión no puede producirse por una simple acumulación: al introducirse la simultaneidad sonora cabe la posibilidad de que el resultado no sea aceptable, de que los sonidos no se mezclen bien entre sí, de que disuenen. Para evitarlo, a los estudiantes de esta forma de ornamentación se les exige un conocimiento absoluto de las posibilidades combinatorias de cada sonido, es decir, de las cuestiones numéricas implicitas en la música, ya que los sonidos combinan o no entre si según la complejidad de la razón aritmética que se forme al considerar las frecuencias de cada uno de ellos. Por eso, la octava, quinta y cuarta son consideradas consonancias perfectas: las razones de sus frecuencias son los términos de la $\tau \epsilon \tau p \alpha \kappa \tau \boldsymbol{v S}$ musical, con los que resuena la armonía de las esferas. El pitagorismo, escondido en las sucesivas oleadas de veneración por la filosofia platónica, ha conseguido sobrevivir, también en la música, a la desaparición del mundo antiguo; no en vano la música se sigue incluyendo en el Quadrivium. En él no se busca que el joven estudiante sepa interpretarla, sino que, como en la Aritmética, se introduzca en la comprensión de los números inteligibles para alcanzar así el punto más elevado en la jerarquía de los estudios medievales. El Quadrivium excede la consideración de artes que se otorga a la Gramática, Retórica y Dialéctica. En el Quadrivium lo que se estudia son las 4 disciplinas, cuya misión es conducir hacia la contemplación ${ }^{88}$ habiendo comprendido el orden de la creación. En la Aritmética, este estudio del orden se realiza considerando los números en su aspecto estable, en sí mismos, como cualidad. Se distingue así de su hermana la Música, porque en ésta lo que se considera es su aspecto móvil, es decir, su proporcionalidad 89 .

El objetivo de los primeros teóricos medievales de polifonia es explicar la técnica correspondiente a la reproducción microcósmica de estos misterios. Según los dos primeros tratados que podemos interpretar inequívocamente ${ }^{90}$, existe un tipo de

ejemplo, Walter ODINGTON, «Diaphonia est concors discordia inferiorum vocum cum superioribus...b, W. ODINGTON, Summa de Speculatione Musicae, American Institute of Musicology, 1970 p. 127. El subrayado es nuestro.

88 A. D. KRESTEFF, "Musica Disciplina and Musica Sonoran, Journal of Research in Music Education 10 (1962). S. CoRBIN, "Musica spéculative et cantus pratique. Le rôle de Saint Augustin dans la transmission des sciences», Cahiers de Civilisation Médiévale 5 (1962).

89 A. REOMENSIS, loc. cit., p. 41.

90 HuCBaldo, De Harmonica Institutione, y Reginus Prumiensis, De Harmo- 
música que ellos denominan organum, con un sustantivo que en su etimologia nos aproxima a la noción de organizar, o sea, introducir un orden, la elevadísima función por medio de la cual la divinidad ha establecido las fuerzas que gobiernan al hombre y al universo. El organum es, pues, evidencia superlativa de la economía divina; a la presencia del santo canto gregoriano une la meticulosa ordenación de la consonancia.

Hucbaldo y Regino, cuidadosos, disciernen entre consonancia y disonancia. Regino, además, remite a la imposibilidad humana de conocer las razones por las que unos sonidos combinan entre sí y otros disuenan. Lo explica con una hermosa alegoria: del mismo modo que a Orfeo le está vedado abrazar a Eurídice, al hombre el comprender las razones profundas de la consonancia musical. Otro tratado da las mismas razones que Regino:

Divinaeque est rationis, et in aliquis inter abditissima naturae latentis... scilicet, quia inter cetera quae adhuc, ex parte et in aenigmate cernimus, haec etiam disciplina hanc ad planum habet rationem in hac vita penetrabilem ${ }^{91}$.

y explica la misma historia de Orfeo y Euridice. Pero Regino y el anónimo autor del Musica Enchiriadis - que durante mucho tiempo se consideró que era Hucbaldo - se remiten independientemente a una fuente latina de gran importancia a lo largo de toda la Edad Media, las Mythologiae de Fulgentius. El conocimiento de Fulgentius se debe a Scotus Erigena y a su discipulo Remigio de Auxerre ${ }^{92}$. Para algunos esto apoya la tesis del origen irlandés de la polifonia. Su sistematización, que es el hecho diferencial que nos importa aquí, aparece a la luz de estas genealogías de conocimientos como efecto del renacimiento carolingio ${ }^{93}$.

Estas fuentes teóricas son todas algo anteriores al año 1000 . Se presentan, pues, cercanas a nuestros primeros libros con notación musical y a los primeros tropos documentados porque surgen en los mismos ambientes y obedecen a inte-

nica Institutione, en M. GERBERT, op. cit., pp. 103-152, y 230-247 respectivamente.

${ }_{91}$ Musica Enchiriadis, atr. falsamente a Hucbaldo, en M. GERBERT, op. cit., p. 172 .

$92 \mathrm{M}$. BUKOFZER, loc. cit.

93 E. FubInI, L'Estetica dall' Antichità al Settecento, Piccola Biblioteca Einaudi, Turín 1976 , pp. 80-83. 
reses similares. Describen dos tipos de organum: uno, por movimiento paralelo de las voces; el otro, con presencia del movimiento oblicuo. Las dos melodías simultáneas ya no han de ser idénticas, y así se introduce un elemento de elección en la composición musical. Este segundo tipo de organum viene justificado en el Musica Enchiriadis por la prohibición del tritono. Pero un cantor que improvisa en movimiento paralelo no tiene necesariamente que hacer ningún tritono ni falsa relación si lo hace a la octava, quinta o cuarta. En todo caso lo que puede hacer es, bemolizando el $s i$, forzar a salirse del modo y empezar asi a dar vueltas por el circulo de quintas ${ }^{94}$. Lo que parece más verosímil es que estos teóricos anduvieran buscando un principio común para dos prácticas polifónicas distintas: el canto paralelo y el canto sobre una nota tenida ${ }^{95}$.

No sabemos cómo sería la realidad sonora que corresponde a la obra de estos teóricos: Jos ejemplos que ellos dan son muy pocos, y desconocemos su representatividad. La primera fuente exclusivamente práctica es la segunda versión del Tropario de Winchester. La primera era de ca. 980, y contenía la versión más antigua del Quem Quaeritis con música. En el siglo XI se copia de él el segundo Tropario y se añade, aparte, un suplemento con las voces organales de unos 150 cantos monódicos de los que se hallan en la primera parte. En el comienzo de esta sección complementaria se les aplica el nombre que encontrábamos en los teóricos y se explica su valoración:

Incipiunt melliflua organorum modulamina super dulcissima caelestia praeconia ${ }^{96}$.

Estas melodías, que no están en forma de partitura sino iseparadas! de los cantos que ayudan a pregonar con más deleite, son absolutamente ininteligibles para nosotros porque están en notación neumática. Lo importante es su aparición dentro de un repertorio de tropos, y su elevado número, que tarda-

94 Precisamente E. E. LowINSKY toma como precedente de la musica ficta los primeros ejemplos documentados de polifonia, en «Secret Chromatic Art re-examinedss, Perspectives in Musicology; op. cit., p. 96.

95 R. H. HoppIN, op. cit., p. 229.

96 Citado en W. APEL. The Notation of Polyphonic Music 900-1600, The Mediaeval Academy of America, Cambridge, Mass. 19535, p. 209. 
remos en volver a encontrar. Aparte de 37 obras varias, el contenido de este añadido polifónico es de un tercio de Aleluyas, otro tercio de cantos responsoriales del Oficio, y el resto tropos de Introitos de la Misa. Predominan, por tanto, las versiones polifónicas de cantos responsoriales, los cantos de solista más melismáticos. Desde aquí, y hasta el siguiente repertorio polifónico de envergadura, se conservan unas catorce fuentes ${ }^{97}$, incompletas o fragmentarias, y casi todas intranscribibles. En una de ellas ${ }^{98}$, que sólo contiene versiones polifónicas de Aleluyas, el organum solamente se aplica en las secciones de solista, práctica que será la norma tiempo después: las partes corales, cantadas al unísono, en monodia; las de solista, en polifonia.

El repertorio polifónico de este siglo XI presenta una cierta unidad por su insistencia en los cantos reponsoriales, y hasta una notable continuidad: a pesar de la escasez de fuentes hay concordancias ${ }^{99}$. Sin embargo, se ignora también su representatividad.

Pronto cambia este panorama: de los siglos XII y XIII, el Monasterio de Saint Martial de Limoges conserva 4 códices con polifonía (unas 64 piezas), en los que no predominan los cantos responsoriales, aunque los hay, sino los tropos $y$ los poemas estróficos latinos: Benedicamus Domino, Secuencias, Versus, Conductus. Se distinguen dos estilos que pueden incluso aparecer en un solo canto. Uno, llamado organum melismático o florido, en que a cada nota del tenor o vox principalis corresponden varias de la voz añadida u organalis; y otro, denominado discanto, en que a cada nota del tenor corresponde aproximadamente otra en la vox organalis ${ }^{100}$.

El predominio de los cantos tropados en el repertorio de Saint Martial y su extensión cronológica hasta el siglo XIII explican que no se pueda considerar, en modo alguno, esta «es-

97 L. B. SPIESS, «An introduction to the Pre-St. Martial Practical Sources of Early Polyphony'), Speculum 22 (1947).

98 Chartres $\mathrm{Ms} 109$.

${ }^{99}$ Por ejemplo, el Kyrie Cunctipotens Genitor, que se encuentra en el tratado Ad organum faciendum y en el $C$. Calixtimus.

100 Hay repeticiones musicales cuando la estructura del texto lo sugiere. En este caso se alterna la ejecución monódica con la polifónica, siguiendo la tradición que ya hemos visto. 
cuela» como preparación de la de Notre Dame. De hecho son dos manifestaciones diferentes, simultáneas ${ }^{101}$.

Estos repertorios anteriores a Notre Dame tienen todos como constante significativa el respeto invariable hacia la auctoritas del tenor. Es de aquí de donde les viene su integridad y su sentido ${ }^{102}$. La otra voz es patrimonio de una elite de cantores muy bien entrenada. De ningún modo puede considerarse al alcance popular, o de peregrinos, etc.

Cuando se escucha o interpreta esta música, percibiendo la complejidad de significados que implica, de correspondencias entre monodía y polifonía, entre texto y música, entre ocasión y estilo, entre sentido y expresión, que la reiteración cotidiana del rito hacía conocer perfectamente, y a la vez se contempla como una unidad gracias a la presencia constante del gregoriano, se recibe con una sensación de profundo enriquecimiento. La multiplicidad ha sido reducida a su origen en la unidad, sin haber desaparecido. Multiplicidad y unidad persisten una en la otra: Dissimilia coniungantur.

\section{ATQUE SIC FINITUR}

En 1163 se coloca la piedra angular de un edificio que conmoverá al mundo: la Catedral de Nuestra Señora. En París; en el lugar en que se instalarán los monarcas Capetos y desde el que dirigirán su política. En el corazón de una idea de la realeza que se extenderá, en oleadas concéntricas, por los territorios más significativos de la cristiandad latina. El día de Pentecostés de 1182 se dedica el Altar Mayor.

Simultáneamente, un Magister Leoninus está trabajando en un encargo ambicioso: crear el repertorio de ornamentos polifónicos que, como una joya más, elevarán el esplendor y el fasto del nuevo lugar sagrado ${ }^{103}$. Sabemos muy pocas cosas de

101 Existe también un Liber Sancti Jacobi o Codex Calixtimus que contiene una guía de peregrinos y la música de Santiago de Compostela; en partícular, la de sus festividades más importantes. En un apéndice se hallan los cantos polifónicos. Entre ellos, un tropo de Benedicamus Domino, que parece ser la pieza a tres voces más antigua conocida.

102 Por esta razón lo consideramos repertorio tradicional.

103 Algunas de las piezas pudieron destinarse al servicio en St. Germainl'Auxerrois. De hecho, hasta la definitiva vinculación de la realeza a la Cité, 
este Leoninus, pero gracias a los apuntes de un estudiante de la segunda mitad del siglo XIII -el llamado Anónimo IV104 - algo más que de los especulativos y artesanos que contribuyeron a levantar las piedras cuidadosamente pensadas y talladas para esta mansión de la Reina de los Cielos. De Leoninus, por ejemplo, dice este Anónimo que

secundum quod dicebatur, fuit optimus organista, qui fecit magnum librum organi de gradali et antifonario pro servitio divino multiplicando ${ }^{105}$.

Era, pues, un organista. Para nosotros, un intelectual de elite; para ellos, algo más que un simple musicus. Su misión iba a ser componer organa para el palacio divino. Para ello organizaria su obra en un solo libro, grande, imponente, magnus. Un libro con la polifonía de gradali et antifonario. Esto es sorprendente porque no existe una tradición anterior que contemple la unificación de Gradual y Antifonario ${ }^{106}$. Leoninus cede a la misma tendencia que lleva a fundir, entre los filósofos, los Libri Variae en Summae 107. Este Liber Organi nacía con el mismo anhelo de totalidad que atribuimos al espiritu gótico, ya que contenia todo el año y en la forma más es-

con Luis IX sobre todo, se realizaban en St. Germain, en tierra firme, funciones de gran esplendor y maravilla. H. HUSMANN, "The enlargement of the Magmus Liber Organi and the Paris Churches St. Germain-I'Auxerrois and Ste. Geneviève-du-Mont», Journal of the American Musicological Society XVI (1963), y por el mismo autor, "The origin and destination of the Magnus Liber Organin, Musical Quarterly 49 (1963). Lo que está fuera de toda duda es la vinculación de la obra atribuida a Leoninus con el desarrollo urbano de París. Las diferencias estilisticas que se aprecian en la música de esta llamada Escuela de Notre Dame, bien pueden reflejar las dos circunstancias de ubicación y cronología.

$104 \mathrm{Se}$ le conoce con el nombre de Anónimo $I V$ porque figura en cuarto lugar en una recopilación de escritos medievales de música, publicada por E. DE CoussemaKer. Scriptorum de Musica Medii Aevi nova series, Paris 1864-1876 (reimpr. Milán 1931), vol. I, pp. 327-365.

105 Anónimo IV, en E. DE CoussemaKER, op. cit., p. 342.

106 Existen algunos libros mixtos. Agradezco a D. A. M. Mundó sus amables indicaciones a este respecto. Es un ejemplo el fragmento $C C$ del Tropario de Winchester, J. HANDSCHIN, loc, cit.

Otro ejemplo, moderno, de organización mixta de los libros litúrgicos es el Liber Usualis, cuyo título mismo ya indica la razón de la unión de ambas partes en una.

107 E. PANOFSKY, Arquitectura Gótica y Escolástica, Infinito, Buenos Aires 1959 (1957), pp. 13-14. 
plendorosa hasta entonces conocida. Esta catedral sonora está, como la de piedra y luz, orientada hacia el sol, pues se abre en la época de Navidad, cuando nace el sol, el sol iustitiae ${ }^{108}$. El Anónimo IV comprendió bien la tarea del Magister, señalando además que era pro servitio divino multiplicando. Parece que, como indicábamos más arriba, la realizó entre 1160 y 1180. Después, el Magnus Liber Organi estuvo en uso

usque ad tempus Perotini magni, qui abbreviavit eundem, et fecit clausulas sive puncta plurima meliora, quoniam optimus discantor erat, et melior quam Leoninus erat ${ }^{109}$.

¿Quién era este Perotinus Magnus? Su nombre se formula, como el de Leoninus, en términos familiares, como si fuera un personaje cercano que admitiera el tratamiento en diminutivo. Sería un curial más. Pero el adjetivo nos avisa: este hombre estaba empapado del mismo espíritu anhelante del Liber, puesto que se le califica con el mismo término, Magnus. El Anónimo IV continúa retratándole cuando dice que melior quam Leoninus erat 110 . Establece asi dos extremos en la música de Notre Dame: no equipara a Leoninus con Perotinus, sino que los contrapone.

Antes de la erección de la fachada principal hacia 1250 , Perotinus trabajó en el Liber. Pero éste no se conserva en su forma original, sino en copias posteriores ${ }^{111}$ que siguen el orden del año litúrgico, empezando en Navidad, y dan solamente la parte polifónica de los cantos correspondientes, omitiendo el resto. Algunas llevan al final una sección adicional que contiene series de clausulae (fragmentos de los cantos de la primera parte destinados a ser opcionalmente insertados en los lugares correspondientes), conducti (poemas estróficos, monódicos, o a dos, tres, o cuatro partes), motetes, y los organa tripla y quadrupla que el Anónimo IV atribuye a Perotinus. Sus sonoridades a tres y cuatro voces elevan la bóveda musical hasta una altura nunca antes conocida ${ }^{112}$.

Predominan de forma absoluta en este Magnus Liber pari-

108 Prophetía Malachiae, 4, 2 y N. PIRROTTA, loc, cit.

109 Anónimo IV, en CousSEMAKER, op. cit., p. 342.

110 Anónimo $I V$, en CousSEMAKER, loc, cit.

111 Principalmente, Wolfenbü̈tel 677 (WI). Wolfenbiutrel 1099 (W2), Fiorencia Plut. 29.1.

112 N. PIRrotTa, loc. cit, 
siense los cantos responsoriales (Graduales y Aleluyas de la Misa, y Responsorios del Oficio), más los Benedicamus Domino. Las cláusulas colocadas al final de $W 1$ y $F$, y los organa quadrupla de Perotinus serian su propia contribución, y los conducti y motetes no habrían formado parte del Magnus Liber Organi nunca, obviamente.

En su forma manuscrita, los cantos responsoriales, convertidos ahora en organa, presentan para ser interpretadas polifónicamente sólo las partes destinadas al solista (Entonación y Verso). El resto se sobrentiende monódico en las fuentes: así es como se articula el fluir litúrgico-musical entre polifonía y monodia, entre ornamento y gregoriano, entre solistas especializados y coro.

En las secciones polifónicas el tenor gregoriano se alarga hasta dimensiones inhumanas, mientras la voz superior, duplum, nueva, florea ágilmente. Cada nota del tenor sostiene las múltiples sinuosidades de la melodía añadida. Actúa asi el tenor como un pilar que soporta el arco melódico de la vox organical13. El tenor, consecuentemente, no necesita ser mesurado; el duplum, en realidad, tampoco (pero se hizo ${ }^{114}$ ). Es el estilo musical conocido como organum purum. Cuando refiriéndose a ello los teóricos del siglo XIII nos hablan de la mensuración del tiempo en el duplum, debe ser porque están intentando explicar una interpretación rapsódica e improvisatoria en los términos de su propio sistema, meticulosamente proyectado para cuantificar la duración de los sonidos ${ }^{115}$. La mensuración del duplum sería el paso intermedio hacia el otro estilo, que, como en Saint Martial, se distingue en la música de Notre Dame, el discantus. Aquí, el duplum, y el tenor con él, se mueven en valores temporales y rítmicos regulares; el tropo, por tanto, prevalece sobre lo tropado. La mensuración se ha extendido al tenor, que, siendo gregoriano, es por esencia inmensurable.

El discanto aparece sobre todo en las cláusulas, tanto en las que ya están colocadas dentro de la pieza correspondiente, como en las que aparecen copiadas por separado al final. En

113 N. PirrotTA, loc. cit.

114 W. APEL. The Notation of Polyphonic Music..., p. 209. Los teóricos del siglo XIII distinguen las obras sujetas o no, en todas sus partes o en algunas a ritmo mensural exacto. N. PIRROTTA, loc. cit.

115 W. APEL, The Notation of Polyphonic Music..., p. 219, y R. H. HoPpIN, op. cit., p. 229,230 . 
ellas, tenor y duplum caminan emparejados, pues a cada nota gregoriana corresponden aproximadamente una o dos de la voz añadida, precisándose el detalle gracias a la mensuración. Para indicarla los copistas no inventaron nuevos signos, sino que recurrieron al repertorio gráfico que ya conocían, es decir, a la notación cuadrada que se venía utilizando para el gregoriano. Por una serie de convenciones, que conocemos gracias a los tratadistas del siglo $\mathrm{XI} \mathrm{I}^{116}$, se deduce la duración relativa de cada nota con respecto a la unidad, según la posición que ocupe, y no según la forma que tenga. La combinación elegida de las duraciones de las notas se repite constantemente en lo que se llama un ordo. Esa célula básica de la repetición se denomina modo, formado por la alternancía de dos valores temporales, uno largo (longa), y otro breve (brevis). Según el De Musica de San Agustín, que es en realidad un tratado de métrica latina ${ }^{117}$, la medida de la larga es el doble de la de la breve, o sea, $\mathcal{y}$ y en nuestra notación musical. Esto significa que todos los ritmos básicos serản ternarios. En los larguisimos melismas del duplum construidos sobre cada sílaba de las secciones en estilo del organum purum, se repiten los modi hasta colmar un ordo. Y se pueden suceder muchos ordines. Estos modi no son, pues, sino pies métricos aplicados a la música. Introducirlos es el reflejo del deseo de introducir Ars, es decir, racionalidad. Tal racionalidad no estaba presente en el gregoriano, puesto que era una revelación inescrutable ${ }^{118}$. Sin embargo, los teóricos justifican la ternariedad resultante diciendo que es "ad similitudinem divinae natura», que «ex tribus constare inveniturs ${ }^{119}$. La justificación por la autoridad de los clásicos sólo se encuentra en el De speculatione musica de W. Odington, de hacia 1300 , y se cree que es un resultado de sus propios estudios anticuarios 120 .

El cantor conocía el modo de un ordo por la fórmula gráfica inicial, que le remití, convencionalmente, a uno de los seis posibles. De esta manera, al igual que la sección del pilar permite inferir la organización de todo el sistema arquitectónico gótico $^{121}$, las fórmulas de la notación modal permiten conocer

116 Véase una primera lista de fuentes en W. APEL. The Notation of polyphonic Music..., pp. 201-202.

117 S. Aurelii Augustini De Musica 1. II, c. III, PL XXXII c. 1102.

118 N. PIRrotta loc. cir.

119 Magister LAMBertus o Ps. ARistóteles, Tractatus de Musica, en Cous. SEMAKER, op. cli., p. 270.

120 W. APEL, The Notation of Polyphonic Music..., p. 222.

121 E. PANOFSKY, op. cit., p. 45. 
la organización del ordo y, consecuentemente, del discurso musical. Para los que conocen estas leyes del modo, la lectura de la notación es sencilla. Cuando se desarrollaran las posibilidades de la cuantificación, el estudio de la escritura musical llegaria a ser un curso completo de música ${ }^{122}$. Esta notación modal, o, hablando estrictamente, la interpretación modal de esta notación, no es necesaria en los organa a dos partes, que se asocian la actividad compositiva de Leoninus. Sólo se hace imprescindible en las obras a más de dos partes, es decir, las atribuidas a Perotinus ${ }^{123}$. Con ello, la humanidad se anexiona territorios superiores y usurpa las funciones divinas. Pues iacaso le es propio al hombre intervenir en los cantos de las jerarquías angélicas? ¿Es que le es licito ponerlos «in mensura et numero, et pondere»? ${ }^{124}$.

Por tanto, no es obligatorio mensurar en Leoninus, pero sí en las cláusulas que se le inserten, e incluso en alguna de las que ya aparecen incluidas dentro de sus organa duobus vocum. Las secciones polifónicas de los cantos responsoriales del Liber se articulan asi en un contraste no sólo estilistico, sino de concepción temporal.

Las cláusulas discantadas son a veces difíciles de identificar, es decir, de localizar el organum al que corresponden y el lugar en que deben reemplazar la composición original. Es que sus dimensiones oscilan entre las más largas que la sección a que sustituyen, y las más breves, con tenores de incluso tres o cuatro notas ${ }^{125}$. Así, las cláusulas tanto pueden amplificar como abreviar la composición ${ }^{126}$.

Cuando se tienen las formas presumiblemente definidas del

122 De hecho, se considera que la notación llegaría a ser el mecanismo esencial del esoterismo musical. Su objetivo no era la fijación o transmisión de una pieza, sino también rodearla de una protección eficaz contra la curiosidad ilícita de los no iniciados. G. DE VAN, "La pedagogie musicale à la fin du Moyen Age», Musica Disciplina 2 (1948). De aqui la autodefensa de W. APEL en The Notation of Polyphonic Music..., p. X.

123 W. APEL. The Notation of Polyfhonic Music..., p. 219.

124 Sap XI, 20. El Magister Lambertus o Ps. ARistóteles, loc. cit., p. 270, al explicar los principios de la mensuración, hace referencia a esta misma expresión biblica.

125 W. G. WAITE, (The abbreviation of the Magnus Libers, Journal of the American Musicological Society 14 (1961).

126 El trabajo básico es: F. LUDWIG, Repertorium Organorum Recentioris et Motetorum Venustissimi Stili, Halle 1910, completado en los de Gennrich, Dittmer, Anderson, Karp y Tischler. Se identifican en ellos los tenores de las cláusulas, y se relaccionan con los organa correspondientes por una numeración aún vigente, aunque confusa. 
Magmus Liber, en su versión más antigua, predomina el estilo del organum purum: las cláusulas son pocas y cortas. Pero en las versiones más modernas sucede lo contrario: al introducir las cláusulas en su lugar, predomina su estilo, el discanto. Entre los dos extremos de la Escuela de Notre Dame hay una evolución del organum purum hacia el discantus ${ }^{127}$ : la introducción de las cláusulas de Perotinus transforma las composiciones más rapsódicas a un estilo totalmente cuantificado en sus valores rítmicos ${ }^{128}$. Del mismo modo que las artes visuales se han articulado en una división exacta y sistemática del espacio, la música se ha clarificado mediante la división exacta del tiempo ${ }^{129}$.

Pero al crecer la longitud de las cláusulas se hacen necesarios tenores igualmente largos. Hubo que recurrir, pues, a la práctica, desconocida hasta entonces, de realizar repeticiontes de fragmentos del tenor con nuevos dupla, para alcanzar la longitud requerida. Esta práctica no figura en la primera fase de la música de Notre Dame. Se originó, por tanto, en el intervalo entre Leoninus y Perotinus. ¿Qué sentido tiene ahora el tenor? Con la práctica de repetir fragmentos del mismo, «prevalecen las consideraciones puramente musicales sobre los requerimientos litúrgicos $)^{130}$. La sacrosancta vetustas del canto que el mismisimo Espiritu Santo habia inspirado a Gregorio el Grande en una escena que reproducen los miniaturistas, se inclina ante la voluntad del hombre. A partir de ahora el tenor pasará a considerarse cantus príus factus, o íncluso res facta, es decir, como material previo, abstracto, para la confección de una nueva estructura basada en consideraciones puramente musicales ${ }^{131}$. Así como en la catedral gótica se ha independizado la forma de la función ${ }^{132}$, en París la música se ha desprendido de la suya: exaltar la palabra divina.

El tamaño de la obra así conseguida, con sus repeticiones que rompen los esquemas interpretativos y conceptuales mantenidos durante siglos, se hace interminable, inconmensurable, incontenible. Nunca antes había sido capaz una estructura mu-

127 R. H. HOPPIN, op. cit., p. 241.

128 W. G. WAITE, loc. cit.

129 E. PANOFSKY, op. cit., p. 35 o P. H. LANG, op. cit., p. 63.

130 N. E. SMITH, "Tenor repetition in Notre Dame organas, Journal of the American Musicological Society 19 (1966).

131 N. E. SMITH, loc. cit.

132 O. VON SIMSON, La Catedral Gótica. Los origenes de la arquitectura gótica y el concepto medieval de orden. Alianza Ed., Madrid 1980 (1956), pp. 31-52. 
sical de sustentar tales magnitudes temporales. Esta es una medida que sobrepasa la capacidad humana ${ }^{133}$. Para su interpretación, en nuestros días se recurre a alternar los cantores, permitiéndoles así la respiración en las largas notas del tenor, o a introducir instrumentos de sonido continuo. Para su comprensión es necesario no considerar cada obra por separado, como, por ejemplo, «el Gradual Viderunt de Perotinus», sino, en todo caso, «la Misa de Navidad en la versión de Perotinus' ${ }^{134}$.

Pero no es solamente la mensuración, la disposición, el tamaño o la proporción, lo que atrae nuestra atención; en la música de la Escuela de Notre Dame encontramos, aún más que en la de Saint Martial, el procedimiento conocido como Stimmtausch, el intercambio de voces, el paso de una voz a otra. Es un mecanismo de interrelación entre las partes de la obra musical. Les preocupó tanto interrelacionar que llegaron a originar el canon más antiguo de la literatura musical conocida. Sabido es que el canon es el más ágil aglutinador de una estructura musical polifónica.

Fuera del Magnus Liber Organi, la otra cara del repertorio polifónico vinculado a Notre Dame la constituye el conductus y el motete. Se origina éste último al añadir a las largas vocalizaciones del duplum, triplum y quadruplum nuevos textos, latinos primeramente, y en la lengua romance después, mientras el tenor continúa con el suyo propio. Esto, cuando sucede en las cláusulas discantadas, ayuda a que se desprendan del organum primitivo. Se oye entonces el tenor gregoriano, un duplum latino, un triplum en francés, todo simultáneamente y fuera del organum. Puesto que, como hemos visto, muchas cláusulas eran muy breves y su tenor constaba de muy pocas notas, al pasar a obras autónomas tuvieron que ser alargadas de nuevo por repetición del tenor, para formar motetes de las dimensiones mínimas. Si el tenor está formado por tres o cuatro notas de un melisma gregoriano deberá ser repetido veinte, treinta veces hasta alcanzar el tamaño requerido. ¿Cómo reconocer que esas dos o tres notas que suenan conti-

133 R. H. HoppIN, op. cit, p. 241.

${ }^{134}$ Según las interpretaciones modernas, su duración se incrementa en aproximadamente de media hora a tres cuartos de hora. La palabra Viderunt del Gradual tarda unos dos minutos y medio en pronunciarse en la versión del Early Music Consort of London, Música de la Era Gótica, Archiv Produktion, 2723045 , Polydor 1976. 
nuamente, escondidas bajo un bosque de textos distintos, fueron en un pasado no muy lejano integrantes de una melodia gregoriana? Imposible. El canto gregoriano, y con él la obra musical sagrada, han saltado en pedazos, se desintegran. Entre la dispersión y la identidad, el motete deberá recurrir a la isorritmia para conservarse.

El conductus, al carecer de tenor gregoriano y de función litúrgica precisa, confundido a veces cuando hay estructura estrófica con el himno, corre también ese riesgo de desintegración. Por ello utilizará artificios constructivistas de un racionalismo impresionante: cambio de voces, repetición de ordines en diferente modo, finales recurrentes a modo de recapitulación, etc., se utilizan en grado sumo.

Las largas vocalizaciones del organum, sobre todo cuando no hay cláusulas, son de dimensiones sobrehumanas, en particular en el tenor. Pero esta dimensión extrema aún conserva un punto de referencia: el tenor gregoriano. En el caso del conductus y del motete la situación es cualitativamente distinta, con sus recursos numerológicos y constructivistas. El sentido de la aparición de estos diseños apunta claramente hacia la integración y unificación del discurso musical. Esta apelación a la unidad no habia sido necesaria mientras la obra musical estuyo ligada a una concepción compacta del rito, pero ahora es inevitable caer en la especulación musical para evitar la dispersión.

Desde este momento la música emprende el camino de la emancipación. Los abismos de la virtualidad se abren ante ella. En los primeros momentos de este proceso se apoyará, como hemos visto, en el diseño formal del texto ${ }^{135}$ o en especulaciones matemáticas y esotéricas. Más tarde encontrará la unidad creando todo un sistema linguístico propio: la tonalidad, y su primogénita, la «forma» musical. Desde el Renacimiento, la música instrumental desarrollará sus propias estructura, abstractas y asemánticas, porque no aluden ya a nada

135 A. Schöenberg se encontró en una situación similar en varias ocasiones. En su período atonal no dodecafónico, y también después del hallazgo del método. En el primer caso, la estructura musical se descargaba en un desgarrado expresionismo; en el segundo, en el texto. De aquí la acusación de que el método era incapaz por si solo de generar estructuras musicales de mayor tamaño. A. Schöenberg, El Estilo y la Idea, Taurus, Madrid 1963 (1951), p. 146. 
que no sea el juego combinatorio entre los sonidos, del mismo modo que las artes visuales, al no poderse remitir a la norma tradicional, deberán refugiarse en principios teóricos.

¿De dónde surgen esas nuevas formas musicales? Se toman de otros campos. De esta manera, en una última pirueta, la música se resiste a la secularización:

con la invención de la fuga y otras formas de composición... la música asume las estructuras del pensamiento mítico en el [preciso] momento en que el relato literario las evacua, de mítico... a novelesco ${ }^{136}$.

El canto gregoriano, sometido a la alquimia de Perotinus Magnus, se ha transmutado en música. De este modo la música se va configurando como una disciplina autónoma 137 . Desprovista ahora de significado numinoso, ¿cuál será su camino en el laberinto de las posibilidades? ¿El esteticismo agónico del Ars Nova y del Ars Subtilior? ¿El expresionismo mimético de la música renacentista? ¿El orgullo desesperado de la tonalidad y la música instrumental? Denn das Schöne ist nicht als des Schrecklichen Anfang.

$136 \mathrm{CL}$ Lévi-Strauss, El Hombre Desmudo. Mitológicas IV, Siglo XXI. México 1976 (1971), p. 589.

137 E. FuBINI, op. cit., p. 91. 